\title{
Pulsatile Tinnitus due to Intracranial Dural Arteriovenous Fistula after Head Trauma by a Golf Ball
}

\author{
Yong Jun Choi ${ }^{1}$, Se In Choi ${ }^{1}$, Jae-Jin Song ${ }^{2}$, and Joo Hyun Park ${ }^{1}$ \\ ${ }^{1}$ Department of Otorhinolaryngology-Head and Neck Surgery, College of Medicine, Dongguk University, Ilsan Hospital, Goyang; and \\ ${ }^{2}$ Department of Otorhinolaryngology-Head and Neck Surgery, Seoul National University Bundang Hospital, \\ Seoul National University College of Medicine, Seongnam, Korea
}

\section{골프공 외상 후 발생한 두개내 동정맥루에 의한 박동성 이명}

최용준 ${ }^{1} \cdot$ 최세인 $^{1} \cdot$ 송재진 $^{2} \cdot$ 박주현 $^{1}$

동국대학교 의과대학 일산병원 이비인후과학교실, ${ }^{1}$ 서울대학교 의과대학 분당서울대학교병원 이비인후과학교실 ${ }^{2}$

\author{
Received April 3, 2015 \\ Revised May 8, 2015 \\ Accepted May 9, 2015 \\ Address for correspondence \\ Joo Hyun Park, MD \\ Department of Otorhinolaryngology- \\ Head and Neck Surgery, \\ College of Medicine, \\ Dongguk University, \\ Ilsan Hospital, 27 Dongguk-ro, \\ Ilsandong-gu, Goyang \\ 410-773, Korea \\ Tel $+82-31-961-7436$ \\ Fax +82-31-961-7427 \\ E-mail parkzzu19@dongguk.ac.kr
}

Diagnosis of traumatic arteriovenous fistula (AVF) is usually delayed because it takes time to be enlarged enough to emerge radiologically or because symptoms occur a few months after the trauma. A 56-year-old woman presented with a newly developed tinnitus immediately after a head trauma. Pulsatile high-frequency tinnitus was heard also by examiner and recorded using a transcanal microphone. Angiography revealed an intracranial dural AVF fed by the middle meningeal artery, draining the superior sagittal sinus on the affected side. After percutaneous transarterial embolization, tinnitus successfully disappeared. The clinical presentation, radiologic and angiographic features, and management are discussed. To our knowledge, this is the first reported case of pulsatile tinnitus caused by AVF developed immediately after a trauma. We emphasize that precise physical examination, laboratory tests, and appropriate radiographic imaging are essential for accurate diagnosis and treatment when a patient presents with pulsatile tinnitus, especially after a head trauma.

Korean J Otorhinolaryngol-Head Neck Surg 2015;58(8):589-93

Key Words Arteriovenous fistula $\cdot$ Embolization $\cdot$ Pulsatile tinnitus.

\section{Introduction}

Tinnitus can be subclassified as either pulsatile or non-pulsatile based on the perceived quality of sound. Of them, pulsatile tinnitus (PT) is an auditory perception of heartbeat-synchronous sound, which is usually caused by vascular abnormalities. ${ }^{1)}$ If PT is also audible by the examiner, it is also described as objective PT. ${ }^{1)}$ Intracranial dural arteriovenous fistula (AVF) is one of the causes of PT. Dural AVF designates an abnormal direct connection between dural arteries and dural veins or a venous sinus, and accounts for approximately $10-15 \%$ of intracranial arteriovenous malformations. ${ }^{2,3)}$ Dural AVFs are predominantly idiopathic, but a small percentage of patients have a history of previous craniotomy, trauma, or dural sinus thrombosis. ${ }^{4)}$ The most common causes of traumatic AVFs are penetrating injuries to adjacent arteries and veins or iatrogenic sequelae of medical procedures. ${ }^{5)}$ Diagnosis of traumatic AVFs are usually delayed for 2-6 months, because their clinical manifestations are quite variable and it takes time to be enlarged enough to emerge radiologically. ${ }^{6}$ Previous researchers have reported PT caused by traumatic AVF and its treatment. ${ }^{78}$ ) In most cases, tinnitus symptom occurred a few months after trauma, ${ }^{7,8)}$ and there have been no reported cases of objective PT developed immediately after trauma by traumatic AVF. In the current study, we report a case of a traumatic AVF presenting as newly developed objective PT immediately after head 
trauma by a golf ball, focusing on the diagnostic approaches.

\section{Case}

A 56-year-old woman was admitted to our neurosurgery department due to a skull fracture of the left parietotemporal bone and left subarachnoid hemorrhage after head trauma caused by a golf ball. She complained headache, mild dysarthria, mild motor weakness of right upper extremity. The patient presented with newly developed PT immediately after trauma and was referred to the department of otorhinolaryngology. She complained of heartbeat-synchronous sound perception in the left ear, which she described as a 'whoosh ... whoosh' sound, which was aggravated by neck flexion. She denied other otologic symptoms. Her past medical history was non-remarkable.

On physical examination, her left parietotemporal area showed mild bony depression by fracture with skin laceration. Her tympanic membrane and external auditory canal
(EAC) findings were normal. When the examiner approached to the left temporal area closely, high-pitched pulsatile sound was audible without any aid of an instrument. The pulsatile sound was also clearly detected on auscultation using a stethoscope, and the sound was most clearly audible on the left parietal area. In addition, the intensity of the sound increased when her neck was rotated to the left side or flexed, and decreased when the neck was rotated to the right side or when the left side of the neck was manually compressed. Her neurological examination was non-remarkable.

Averaged hearing thresholds (average of 0.5, 1, 2, and 4 $\mathrm{kHz}$ ) of right and left sides were 23 and $28 \mathrm{~dB}$, respectively, by pure tone audiometry. Both ears exhibited moderate sensorineural hearing loss only at $8 \mathrm{kHz}$, and of note, her audiogram revealed a higher threshold for the left ear $(35 \mathrm{~dB})$ than the right ear $(20 \mathrm{~dB})$ at $1 \mathrm{kHz}$ (Fig. 1A). Speech discrimination was $100 \%$ and tympanometry showed type A curves for both ears.

An EAC-sealing omnidirectional condenser microphone

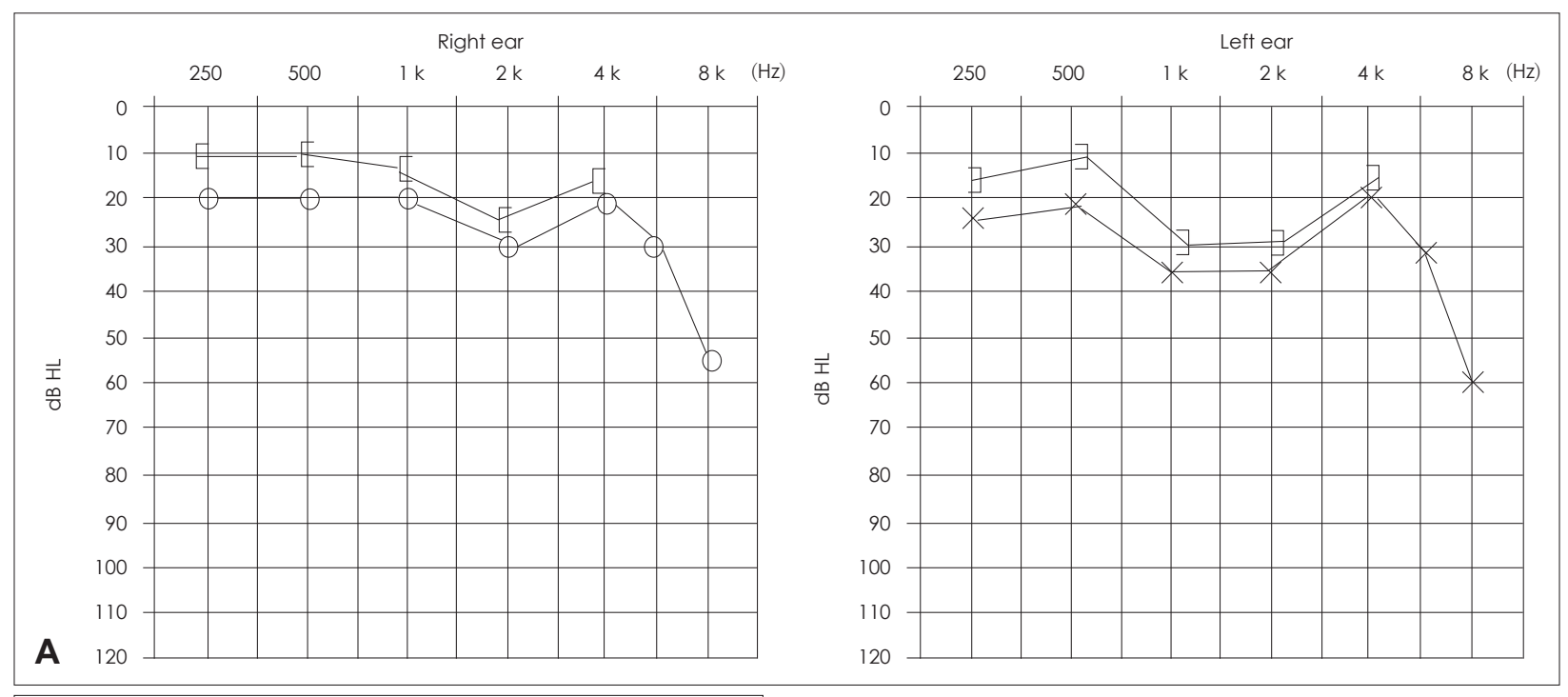

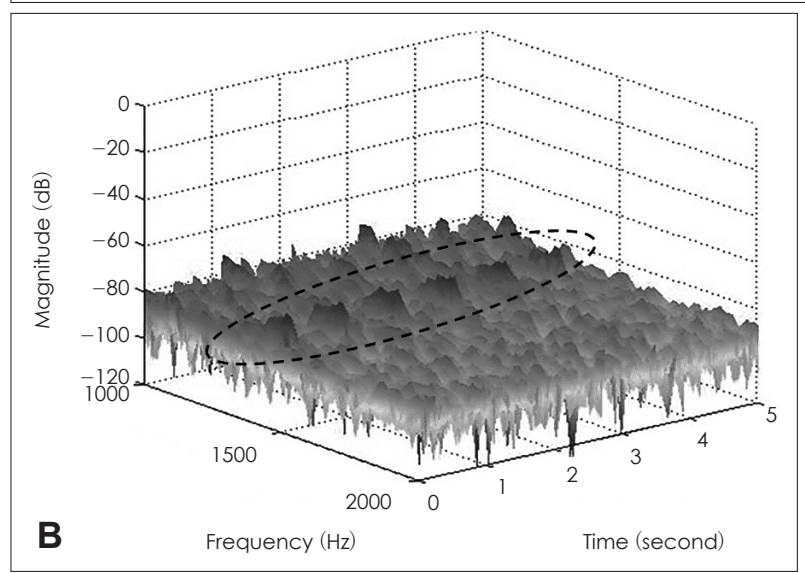

Fig. 1. Pure tone audiometry and spectrogram of pulsatile tinnitus. Audiometry showed a higher threshold for the left ear than the right ear at $1 \mathrm{kHz}(\mathrm{A})$. Periodic high-frequency sound was recorded mainly at around $1500 \mathrm{~Hz}$ (dotted circle) in spectrogram (B). 
(Lavalier, RODE microphones, Sydney, Australia) was used to record the sound pressure wave generated by the PT. The signal was recorded using Cubase 5.0 software (Steinberg Media Technologies GmbH, Hamburg, Germany) at a sampling rate of $44100 \mathrm{~Hz}$, and the recorded signal was analyzed using MATLAB R2013a (The MathWorks, Natick, MA, USA). The spectrogram revealed prominent pulsatile bumps around $1500 \mathrm{~Hz}$ (Fig. 1B, denoted by a dotted circle). These pulsatile bumps appeared as chirp-like and were consistent with the subject's and physician's descriptions of the sound quality. Considering the relatively higher hearing thresholds at 1 and $2 \mathrm{kHz}$ on the left side, masking by PT may have elevated thresholds at 1 and $2 \mathrm{kHz}$.

Brain CT angiography revealed tortuous vascular change of the left internal maxillary artery accompanied by multiple venous structures, suggesting an AVF (Fig. 2A and B). In view of its location and the character of tinnitus, this vascular lesion was presumed to be the cause of her PT. Subsequent transcranial carotid angiography demonstrated an intracranial dural AVF with arterial supply emanating from the left middle meningeal artery with venous drainage into the superior sagittal sinus through meningeal vessels (Fig. 2C and D). The lesion was treated by transarterial embolization using transarterial Onyx ${ }^{\circledR}$ (ethylene vinyl alcohol copolymer, ev3 Neurovascular, Irvine, CA, USA). Angiography performed immediately after embolization confirmed successful obliteration of the dural AVF (Fig. 3). PT completely disappeared immediately after the intervention, and the patient was discharged 3 days after embolization without any post-treatment complication. She did not report any recurrent symptom of PT at the outpatients' clinic during her six-month follow-up.

\section{Discussion}

PT is a perception of rhythmic sound produced outside the inner ear without an external stimulus that usually originates
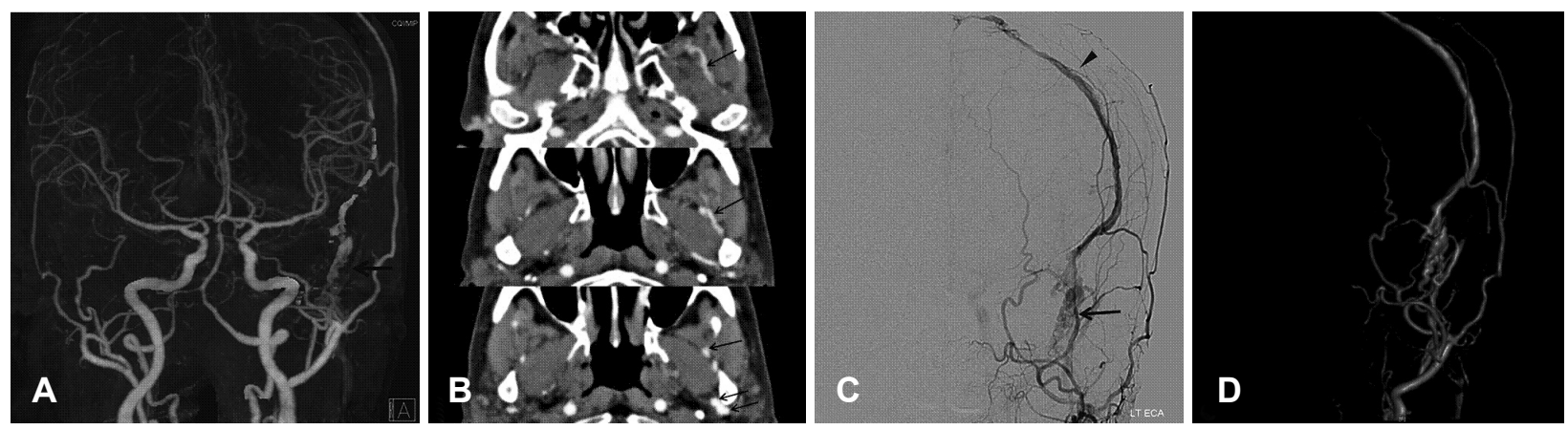

Fig. 2. Tortuous vascular changes of branches from the middle meningeal artery were observed (arrow) in arterial phase by CT angiography (A). Axial scans of brain CT (B) showed tortuous prominent arterial feeders from left external carotid artery in left masticator space (arrow). Left external carotid artery angiography (C) and 3D reconstruction angiography (D) revealed a dural arteriovenous fistula fed by the middle meningeal artery (arrow) and draining into the superior sagittal sinus through meningeal vessels (arrowheads).
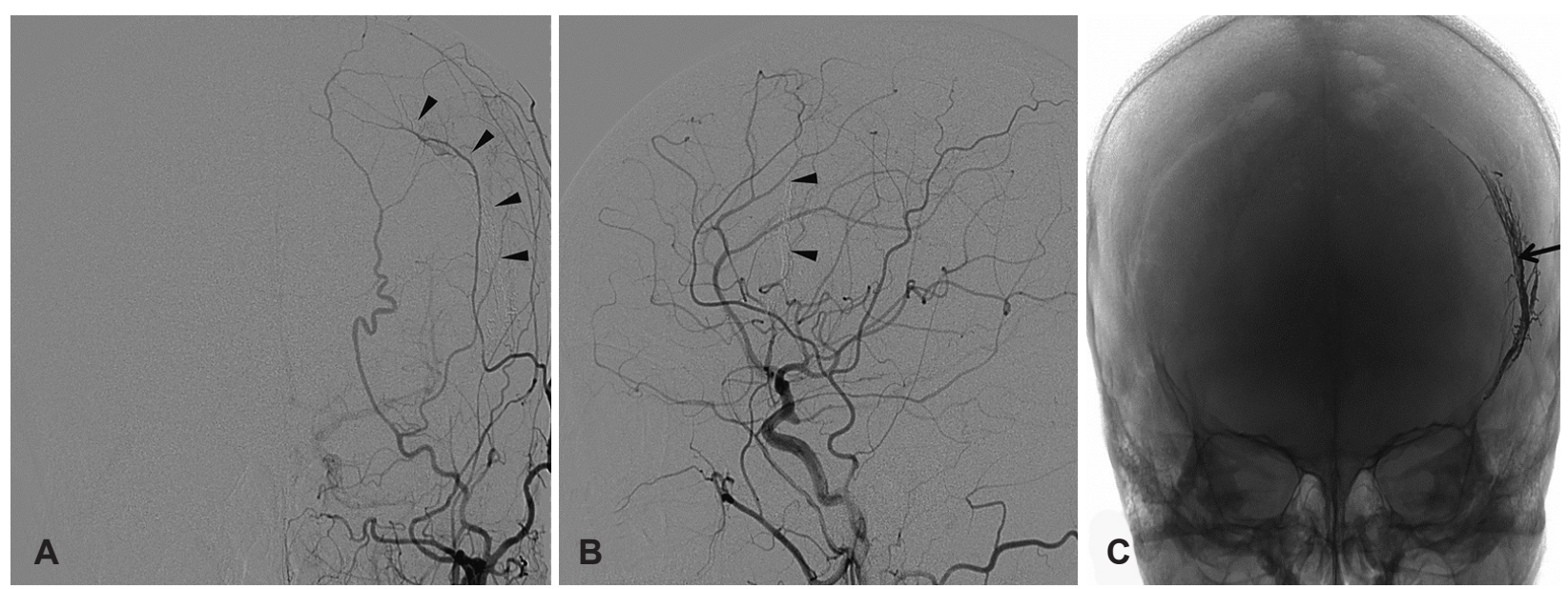

Fig. 3. Left external carotid angiogram obtained immediate after embolization. Coronal (A) and sagittal (B) views demonstrating complete obliteration of the left dural arteriovenous fistula from the middle meningeal artery (arrowheads). Cranial radiograph after transarterial embolization $(C)$ showing the liquid embolic agent (Ony $x^{\circledR}$, ev3 Neurovascular, Irvine, CA, USA, arrowheads) filling the middle meningeal artery. 
from a vascular etiology. It may be caused by turbulent blood flow generated by increased flow volume or vessel stenosis, and may be of arterial or venous origin. PT can be caused by arterial lesions, such as, arteriovenous shunts, intracranial aneurysms, carotid artery dissections, glomus tumors, or atherosclerosis or fibromuscular dysplasia of the carotid artery. The venous origins of PT include benign intracranial hypertension, jugular bulb abnormalities, dural sinus stenosis, and sigmoid sinus diverticulum or dehiscence. ${ }^{9)}$

PT is an infrequent otologic symptom, but precise history taking and physical examinations are important aspects of its curability after making an accurate diagnosis. As demonstrated by the current case, periauricular, periorbital, cranial, and cervical auscultation are important for detecting objective PT and bruits, and trans-canal recording provides a means of objectifying PT in selected cases. Diagnosis is dependent on clinical suspicion arising from history-taking and physical examination, and high-resolution imaging, such as, contrast-enhanced CT or magnetic resonance imaging should be performed in most cases. Also, conventional carotid angiography must be performed when there is a possibility of a vascular malformation or AVF.

Dural AVF has been reported in $2-20 \%$ of patients with normal otoscopic findings and objective $\mathrm{PT}^{10)}$ The transverse, sigmoid, and cavernous sinuses are the most common sites of dural AVF, and they are fed by branches of the external carotid artery. ${ }^{11)}$ The majority of dural AVFs are asymptomatic, but clinical manifestations arise from incidental findings to aggressive presentations, which include intracranial hemorrhage and neurologic deficits that require immediate intervention. Common symptoms are PT, headache caused by an elevated intracranial pressure (ICP), and visual impairments. ${ }^{11)}$ Trauma is the underlying cause in $20 \%$ of dural AVF cases, ${ }^{12)}$ and a few cases of post-traumatic dural AVF have been reported (Table 1). Cross-sectional imaging techniques, such as, CT or MR angiography aid diagnosis, but conventional angiography continues to provide the most accurate means of completely characterizing and classifying dural AVFs.
Majority of patients with dural AVF is idiopathic. Diagnosis of traumatic dural AVF is usually based on clinical history such as previous skull surgery, craniofacial trauma, dural sinus thrombosis or risk factors for venous thrombosis to differentiate it from idiopathic dural AVF. ${ }^{4}$ Heritable risk factors for venous thrombosis including antithrombin, protein C, and protein $\mathrm{S}$ deficiencies, have been known to be associated with occurrence of dural AVF. Symptoms related to location of dural AVF and pattern of venous drainage regardless of etiology. ${ }^{5)}$

Traumatic dural AVF should be treated as soon as possible. During the early stages, treatment is easier because there is no vascular scar tissue, collateral circulation, or anatomical distortion. On the other hand, in a longstanding fistula frequently results in serious complications, such as, fistula rupture, neuropathy, distal embolus, or thrombosis. ${ }^{13)}$ Davidovic, et al. ${ }^{14)}$ reported an average time between injury and treatment of about 13 months for traumatic AVF, and that only $8 \%$ of AVFs were diagnosed within 24 hours of trauma, whereas Rich and Hobson $^{15)}$ reported an average delay to treatment for traumatic AVF of 2-6 months in half of cases. Furthermore, extension of the distal vein occurs slowly, which can delay diagnosis, ${ }^{15)}$ and symptoms due to AVF rarely occur immediately after trauma. In our case, we consider that increased ICP due to subarachnoid hemorrhage resulting from the skull compression fracture probably contributed to early AVF formation.

Our patient complained of PT immediately after trauma and left-sided objective PT was auscultated during physical examination. Transcanal recording of PT played a role in consolidating clinical suspicion of AVF and subsequently choosing the right imaging modality, and an AVF was diagnosed by contrast-enhanced CT and conventional angiography. The AVF was successfully treated by transarterial embolization, and the patient became symptom-free immediately after intervention. We emphasize that precise physical examination, laboratory tests, and appropriate radiographic imaging are essential for accurate diagnosis and treatment when a patient presents with PT, especially after head trauma.

Table 1. Reported cases of post-traumatic pulsatile tinnitus

\begin{tabular}{lcccc}
\hline & Sex/age & Cause & Duration from trauma to diagnosis (months) & Treatment \\
\hline Al-Ghamdi, 1998 & M/43 & Aneurysm & 24 & Surgical removal \\
Park, et al. ${ }^{8)}$ & F/38 & AVF & $2-3$ & Transarterial embolization \\
Chae, et al. & M/31 & AVF & 2 & Transarterial embolization \\
Verde, et al. 2003 & F/28 & AVF & 12 & Self resolution \\
Tan, et al. 2008 & F/40 & AVF & 10 & Transarterial embolization \\
\hline
\end{tabular}

F: female, M: male, AVF: arteriovenous fistula 


\section{Acknowledgments}

This work was supported by a grant of the Korea Health Technology R\&D Project through the Korea Health Industry Development Institute (KHIDI), funded by the Ministry of Health \& Welfare, Republic of Korea (grant number HI14C2264).

\section{REFERENCES}

1) Langguth B, Kreuzer PM, Kleinjung T, De Ridder D. Tinnitus: causes and clinical management. Lancet Neurol 2013;12(9):920-30.

2) Kwon BJ, Han MH, Kang HS, Chang KH. MR imaging findings of intracranial dural arteriovenous fistulas: relations with venous drainage patterns. AJNR Am J Neuroradiol 2005;26(10):2500-7.

3) Newton TH, Cronqvist S. Involvement of dural arteries in intracranial arteriovenous malformations. Radiology 1969;93(5):1071-8.

4) Chung SJ, Kim JS, Kim JC, Lee SK, Kwon SU, Lee MC, et al. Intracranial dural arteriovenous fistulas: analysis of 60 patients. Cerebrovasc Dis 2002;13(2):79-88.

5) Gandhi D, Chen J, Pearl M, Huang J, Gemmete JJ, Kathuria S. Intracranial dural arteriovenous fistulas: classification, imaging findings, and treatment. AJNR Am J Neuroradiol 2012;33(6):1007-13.

6) Seaton DL. Traumatic arteriovenous fistula of the leg. An easily missed diagnosis. J Fam Pract 1998;46(3):247-50.

7) Chae SW, Kang HJ, Lee HM, Hwang SJ. Tinnitus caused by traumatic posterior auricular artery--internal jugular vein fistula. $\mathrm{J}$
Laryngol Otol 2001;115(4):313-5.

8) Park SY, Kim SC, Lee KS, Lee KJ. A case of the pulsatile tinnitus due to Post-traumatic arteriovenous fistula involving superficial temporal artery treated with percutaneous embolization. Korean J Otolaryngol-Head Neck Surg 2000;43(6):667-9.

9) Liyanage SH, Singh A, Savundra P, Kalan A. Pulsatile tinnitus. J Laryngol Otol 2006;120(2):93-7.

10) Waldvogel D, Mattle HP, Sturzenegger M, Schroth G. Pulsatile tinnitus--a review of 84 patients. J Neurol 1998;245(3):137-42.

11) Christie A, Teasdale E. A comparative review of multidetector $C T$ angiography and MRI in the diagnosis of jugular foramen lesions. Clin Radiol 2010;65(3):213-7.

12) Piippo A, Laakso A, Seppä K, Rinne J, Jääskeläinen JE, Hernesniemi $\mathrm{J}$, et al. Early and long-term excess mortality in 227 patients with intracranial dural arteriovenous fistulas. J Neurosurg 2013;119(1): 164-71.

13) Schellack JV, Jones TR, Frusha JD, Deumite NJ. Chronic femoral arteriovenous fistula masquerading as the postphlebitic syndrome. J La State Med Soc 1991;143(9):22-7.

14) Davidovic LB, Banzić I, Rich N, Dragaš M, Cvetkovic SD, Dimic A. False traumatic aneurysms and arteriovenous fistulas: retrospective analysis. World J Surg 2011;35(6):1378-86.

15) Rich NM, Hobson RW 2nd, Collins GJ Jr. Traumatic arteriovenous fistulas and false aneurysms: a review of 558 lesions. Surgery 1975; 78(6):817-28. 